\title{
ANALISIS EKSPLANATORI FAKTOR DAYA SAING INDUSTRI KECIL (Studi Pada Sentra Industri Kecil Batik Di Kota Jambi).
}

\author{
Mulyadi Raf \\ Fakultas Ekonomi, Universitas Jambi, Indonesia \\ Email: mulyadi59@yahoo.com
}

\begin{abstract}
Abstrak
Penelitian ini menganalisis faktor-faktor yang dapat meningkatkan daya saing batik tradisional Jambi. Teori daya saing yang digunakan dari teori Rostow (1999) dan Porter (2000). Survei dilakukan terhadap 49 pemilik dan 100 perajin batik. Metode analisis faktor dan regresi berganda menggunakan software SPSS 15.00. Hasil analisis regresi berganda membuktikan variabel Produk, Infrastruktur, Kebijakan Pemerintah, SDM dan IPTEK secara simultan berpengaruh sebesar 75,8\% meningkatkan daya saing batik Jambi. Secara parsial variabel Infrastruktur, SDM dan IPTEK mempengaruhi Daya Saing batik Jambi.
\end{abstract}

Kata Kunci: IKM, Daya Saing, Batik Tradisional Jambi.

\begin{abstract}
This study analyzed the factors that can increase the competitiveness of traditional batik Jambi. It used Competitiveness theories of Rostow (1999) and Porter (2000). The survey was conducted on 49 SMEs, 100 owners and handicraftsmen. It used factor analysis and multiple regressions using SPSS software 15.00. The results proved that the variable Products, Infrastructure, Government Policies, Human Resourcesand Science and Technology simultaneously have influenced $75.8 \%$ to increase competitiveness batik Jambi. Partially variable Infrastructure, Human Resources and Science and Technology affected the competitiveness of batik Jambi.
\end{abstract}

Keywords: SMEs, Competitiveness, Traditional Batik Jambi.

\section{PENDAHULUAN}

Komoditi Industri Kecil Menengah (IKM) yang memiliki daya saing, memiliki potensi dan keragaman yang menitikberatkan pada kerajinan rakyat adalah batik tradisional. Industri dan kerajinan batik merupakan salah satu sektor industri kreatif yang berpotensi dalam memberikan kontribusi dan solusi pada persoalan-persoalan lingkungan, sosial dan ekonomi bangsa (Devina, 2010). Pada sentra kerajinan batik di wilayah Seberang Kota Jambi hanya sekitar 30 persen dari 168 IKM yang khusus memproduksi batik khas daerah Jambi yang masih beroperasi dalam memproduksi batik Jambi, sisanya gulung tikar. Hal ini merupakan fenomena yang menunjukkan bahwa industri batik Jambi mengalami penurunan produktivitas dan pangsa pasar. Penurunan produktivitas akan menyebabkan berkurangnya pangsa pasar karena ketidakmampuan memenuhi permintaan pasar, menurunnya kesejahteraan perajin dan itu berarti masih rendahnya daya saing IKM batik (Tambunan, 2011). Menurut informasi dari Dinas Perindustrian dan Perdagangan Provinsi Jambi (2011) beberapa kondisi negatif di lapangan menunjukkan bahwa perkembangan batik Jambi masih rendah yang disebabkan oleh beberapa hal di bawah ini:

1. Jumlah perajin dan IKM batik Jambi semakin berkurang.

2. Tidak ada standarisasi harga pasar hasil-hasil produksi.

3. Masih kurangnya pemanfaatan daya modal kerja dan sarana prasarana pemasaran yang hanya berorientasi lokal.

4. Keterampilan, dan ketersediaan tenaga kerja serta prasarana produksi modern kurang memadai.

5. Biaya produksi dan tenaga kerja di Jambi cenderung lebih tinggi.

\section{LANDASAN TEORI DAN HIPOTESIS}

Daya saing merupakan kombinasi dari kinerja perdagangan yang mendukung dari kemampuan internal dan eksternal sautu industry untuk memiliki keunggulan bersaing dalam pasar industry yang sama maupun industry yang berbeda. Menurut Rostow (1999) daya saing adalah kemampuan kita untuk memproduksi barang atau jasa yang meme- 
nuhi uji persaingan internasional sementara para warga negara kita menikmati standar yang berkesinambungan (dalam Theodurus, 2007).

Berbagai definisi tentang industri kecil telah banyak diuraikan dan diungkapan oleh para penulis atau pun para peneliti baik dari dalam negeri maupun peneliti dari luar negeri; yaitu: Menurut Badan Pusat Statistik (2010) industri kecil adalah sebuah industri yang mempunyai tenaga kerja 5 (lima) sampai 19 (Sembilan belas) orang tenaga kerja yang terdiri dari kerja kasar yang dibayar, pekerja pemilik dan pekerja keluarga yang tidak dibayar.

Perkembangan kesenian batik dari zaman Majapahit hingga saat ini mejadikan batik bagian dari satu catatan sejarah bangsa. kesenian batik adalah sebuah kesenian Gambar diatas kain yang mejadi salah satu kebudayaan keluarga raja-raja zaman dahulu dan menjadi tren busana daerah yang memiliki keunggulan bersaing dan menjadi kreasi busana dari daerah tertentu (Devina, 2010; Arfan et al., 2008).

Faktor-faktor yang mempengaruhi pengembangan kreativitas industri kecil batik pada: (1) variabel SDM kreatif yaitu motivasi, bakat/minat, komunikasi, dan kompetensi; (2) variabel pekerjaan kreatif yaitu pekerjaan, kepemimpinan, dan kewirausahaan; (3) variabel konteks organisasi yaitu kinerja perusahaan, kebijakan, struktur dan budaya organisasi, serta sistem komunikasi; (4) variabel lingkungan yaitu pemberdayaan sumber daya eksternal, teknologi, persaingan, dan peraturan pemerintah; (5) variabel inovasi produk yaitu desain, bahan, alat, dan pemanfaatan limbah batik. Secara keseluruhan, pada semua variabel terdapat faktor-faktor yang mendukung pengembangan kreativitas (Simatupang, 2008).
Hasil Penelitian Arfan et al. (2008) mengatakan bahwa faktor-faktor yang mempengaruhi pengembangan kreativitas industri kerajinan batik adalah SDM yang tinggi dan peran pemerintah. Hasil studi dari Simatupang (2008) menunjukkan bahwa masih terdapat beberapa permasalahan di sentra industri batik antara lain rendahnya kreativitas, baik dari segi desain, efisiensi dan kualitas.

Hasil Penelitian Daryono \& Wahyudi (2008) menunjukkan bahwa usaha kecil dan menengah idealnya memang membutuhkan peran dan campur tangan dari pemerintah dalam peningkatan kemampuan bersaing, serta mengeluarkan kebijakan atau peraturan yang lebih memihak industri kecil dalam pemberian kredit, peningkatan keunggulan SDM IKM batik dan kualitas produk batik dengan adanya keterbukaan pasar global harus memiliki kompetensi inti utama dalam daya inovasi dan kompetensi manajemen harga.

Hasil Penelitian Rahayu \& Putri (2010) menunjukkan rancangan perbaikan kualitas produk batik solo dengan menerapkan model Quality Function Deployment ( $Q F D$ ), dari hasil penelitian itu juga menunjukkan bahwa kualitas produk batik solo masih belum sebaik kualitas produk batik pekalongan. Hal tersebut terlihat pada rata-rata competitive satisfaction sebesar 3,42. Agar produk yang dihasilkan mempunyai kualitas dan daya saing tinggi, maka perusahaan harus mampu memenuhi kebutuhan dan keinginan konsumen, dimana hal tersebut dapat dicapai dengan melakukan perbaikan kualitas.

Kerangka konseptual tentang hubungan antara faktor-faktor yang mempengaruhi Daya Saing IKM dan pengembangan model Piter (2002), Theodurus (2007), dan Arfan et al. (2008) dalam Gambar 1.

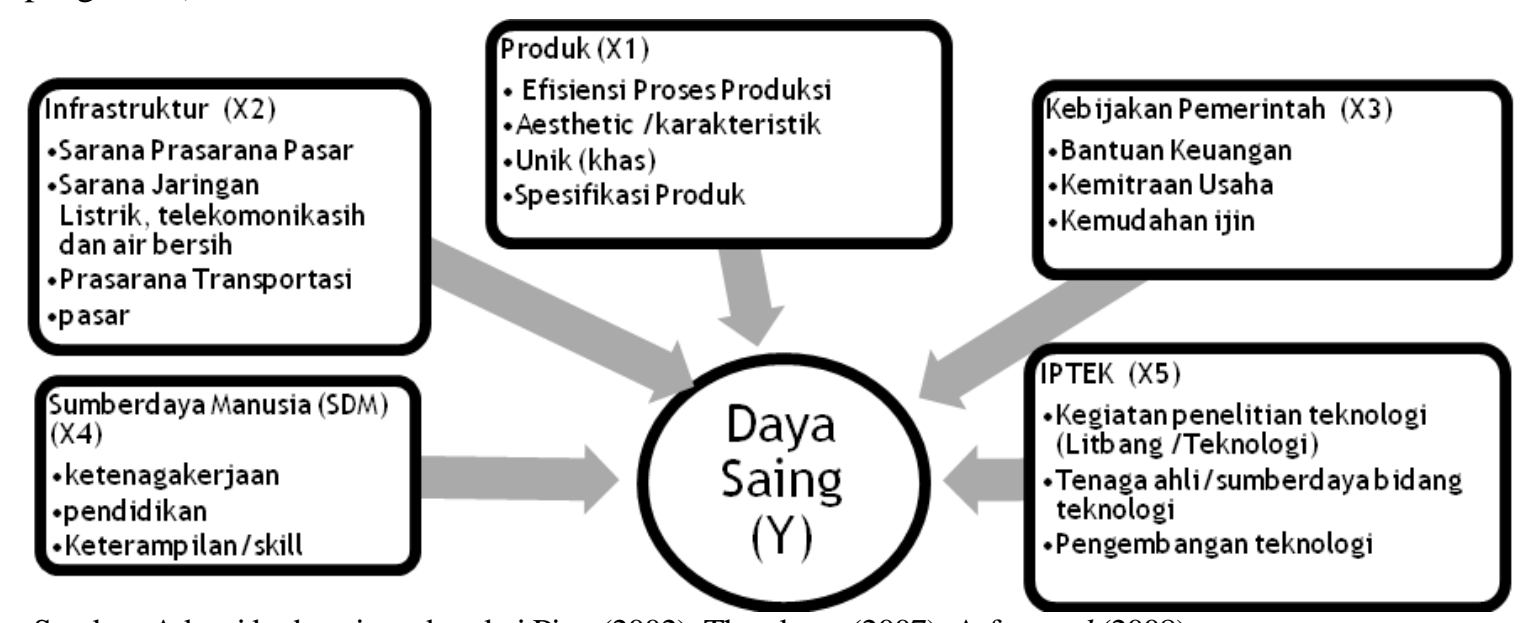

Sumber: Adopsi berbagai sumber dari Piter (2002); Theodurus (2007); Arfan et al.(2008)

Gambar 1. Kerangka Konseptual Penelitian 


\section{Hipotesis}

$\mathrm{H}_{1}$ : Bahwa Faktor Produk (X1), Faktor Infrastruktur (X2), Faktor Kebijakan Pemerintah (X3), Faktor SumberDdaya Manusia (X4) dan Faktor IPTEK (X5) secara simultan mempunyai kontribusi yang signifikan terhadap Daya Saing IKM batik Jambi.

$\mathrm{H}_{2}$ : Bahwa faktor Produk (X1), dan faktor Kebijakan Pemerintah (X3) secara parsial mempunyai pengaruh yang dominan terhadap Daya Saing IKM batik Jambi

\section{METODE PENELITIAN}

Penelitian ini merupakan penelitian survei yang mengeksplorasi dan menganalisis variabel bebas dan terikat yang terdiri dari Produk (X1), Infrastruktrur (X2), Kebijakan Pemerintah (X3), SDM (X4) dan IPTEK (X5) dan Daya Saing (Y), dengan analisis faktor mengekstrasi faktor-faktor Daya Saing menjadi beberapa variabel bebas, yang akan dianalisis menggunakan regresi berganda untuk menemukan variabel bebas yang berkontribusi signifikan terhadap variabel Daya Saing IKM batik Jambi.

Populasi penelitian seluruh perajin dan pemilik usaha IKM batik di Jambi sebanyak 260 orang. Sampel penelitian ini menggunakan teknik pengambilan sampel purposive sampling. Karakteristik responden ada dua kelompok yaitu: Perajin batik: (1) mempunyai keterampilan teknik batik tradisional, (2) pernah mengikuti pelatihan batik. Sebagai pemilik batik: (1) memiliki karyawan > 5 orang, (2) pernah mendapatkan bantuan pelatihan, sarana dan prasarana dari dinas terkait (3) masih memproduksi batik tradisional Jambi dan (4) sebagai perajin batik. Dari karateristik sampel, maka dalam penelitian ini ada 149 responden yang terdiri dari 49 orang sebagai pemilik sekaligus perajin batik dan 100 orang perajin batik.

Jenis data penelitian yaitu data primer yang diperoleh dari kuisioner, pengamatan dilapangan dan wawancara kepada responden. Data sekunder diambil dari instansi terkait dengan pembinaan IKM batik seperti Bappeda, Dinas Perindustrian dan Perdagangan. Teknik pengambilan data menggunakan wawancara, untuk keperluan wawancara peneliti menggunakan instrumen berupa kuisioner dan penyusunan kuisioner dengan memperhatikan panduan definisi operasional dan pengukuran variabel yang telah ditetapkan. Dokumentasi data yang diperoleh dari dokumen IKM batik Jambi dan instansi terkait.
Teknik analisis data menggunakan analisis deskriptif untuk menggambarkan karakteristik responden, penyajian informasi perkembangan IKM batik Jambi. Teknik analisis menghitung nilai mean untuk melihat rata-rata distribusi frekuensi subyek dan obyek penelitian dan disajikan dalam bentuk gambar dan tabel.

Analisis faktor untuk mengekstrasi faktor Daya Saing yang akan dijadikan variabel dan dilanjutkan dengan analisis validasi dan reliabilitas intrumen penelitian. Uji asumsi klasik dilakukan sebagai syarat untuk regresi berganda, regresi berganda digunakan untuk melihat pengaruh variabel bebas terhadap variabel dependen secara parsial (nilai uji t) dan simultan (nilai uji F). Pengolahan data menggunkan SPSS windows versi 15.

\section{HASIL PENELITIAN DAN PEMBAHASAN}

\section{Deskripsi Sejarah Batik Jambi}

Dari segi pembuatannya batik ada 3 macam yaitu Batik Tulis, Batik Cap dan Printing. Batik Cap Jambi telah dikembangkan dengan batik kreasi yang mendorong perajin batik untuk modifikasi pewarnaan batik dengan zat kimia danpewarnaan batik Jambi secara tradisional tetap terpelihara dengan bahan pewarna alami dari akar kayu sepang.Upaya yang telah dilakukan Dinas Perindustrian dan Perdagangan Provinsi Jambi dan koperasi batik Dewan Kerajinan Nasional Daerah Jambi untuk meningkatkan pemasaran batik Jambi telah melakukan upaya promosi batik Jambi dengan mengikuti pameranpameran batik di Jakarta dan batik Jambi mendapatkan respon yang baik di pasar dan mendapat perhatian serius dari Pemerintah Pusat.

Saat ini perkembangan IKM batik Jambi masih terpusat pada wilayah Seberang Jambi, namun saat ini sudah banyak pemberdayaan IKM batik di Kabupaten Batang Hari, Kerinci, Sarolangun, Muaro Jambi, Tebo, Merangin dan Muaro Bungo yang memiliki batik dengan ciri khas motif dari masingmasing daerah.

Dalam kurun waktu 37 tahun perkembangan IKM batik Jambi cukup berfluktuasi dan rekapitulasi tersebut dalam Gambar 2. Dari Gambar 2 menunjukkan bahwa perkembangan IKM batik Jambi di sentra industri batik Jambi hanya meningkat $2 \%$ $8 \%$ per tahun atau pertumbuhan dalam 10 tahun antara 2-18 IKM batik, akan tetapi pada tahun 2010 yang masih aktif memproduksi batik Jambi hanya 49 IKM. Untuk perkembangan diversifikasi motif batik Jambi dapat dilihat dalam Tabel 1. 


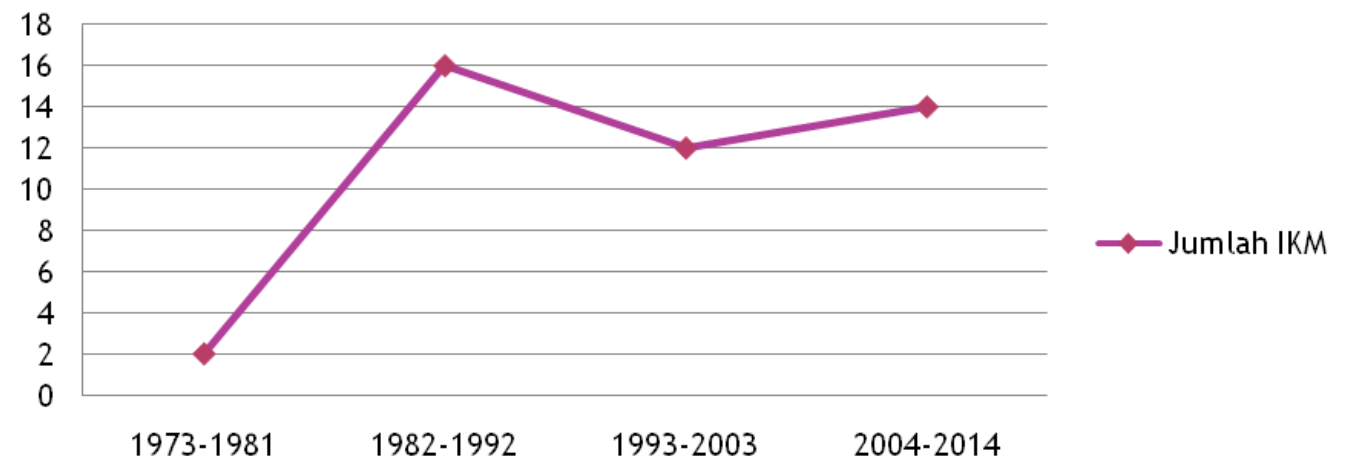

Sumber: Hasil analisis data primer 2011

Gambar 2. Deskripsi Perkembangan Industri Batik Jambi

Tabel 1. Rekapitulasi Motif Batik Jambi

\begin{tabular}{|c|c|c|c|c|}
\hline No & Motif & Motif & Motif & Motif \\
\hline 11 & Duren Pecah & 9 Terung Pirus & 18 Bungo Bangkai & 27 Bungo Nago Sari \\
\hline 2 & Kapal Sanggat & 11 Bungo Kopi & 19 Nanas & 28 Perahu Pencalong \\
\hline 3 & Kuao Berhias & 12 Cumi, & 20 Candi Muaro Jambi & 29 Punai Merindu \\
\hline 4 & Merak Ngeram & 13 Kerang & 21 Lebah Madu Rengas & 30 Sitawa \\
\hline 5 & Tampuk Manggis & 14 Kepiting & 23 Bungo Cabe, & 31 Sidingin \\
\hline 6 & Batanghari & 15 Panah Kubu, & 24 Sialang Raja & 32 Angso duo \\
\hline 71 & Encong kerinci & 16 Daun Jeruk dari Ragam Hias & 25 Serat Kayu & 33 Bungo antelas \\
\hline 8 & Daun Teh & 17 Gajah, & 26 Bungo Sawit & 34 Batanghari \\
\hline
\end{tabular}

Sumber: Dinas Perindustrian dan Perdagangan Jambi (2011).

Tabel 2. Deskripsi Perkembangan Aset IKM Jambi

\begin{tabular}{lcl}
\hline \multicolumn{1}{c}{ Modal Awal } & Tahun & \multicolumn{1}{c}{ Penjualan Rata-rata perbulan } \\
\hline Rp. $5000-$ Rp. 90.000 & $1973-1989$ & Terendah Rp. 1.000 .000 \\
Rp. $100.000-$ Rp. 900.000 & $1990-2000$ & Penjualan tertinggi Rp. 720.000 .000 \\
Rp. $1.000 .000-$ Rp. 50.000 .000 & $2001-2009$ & \\
\hline Sumber: & & \\
\hline
\end{tabular}

Sumber: data primer di olah 2011

Tabel 3. RekapitulasiJumlah Responden

\begin{tabular}{cccc}
\hline Jenis Kelamin & Jumlah Responden & $\%$ & Keterangan Perajin \\
\hline Pria & 9 & $16 \%$ & Peranjin batik 100 orang Perempuan \\
Wanita & 140 & $84 \%$ & \\
Total & 149 & $100 \%$ & \\
\hline
\end{tabular}

Sumber: Data Primer (diolah 2011)

Variasi motif batik Jambi cukup banyak dan setiap motif batik memiliki arti yang berbeda, misalnya motif batik duren pecah artinya melaksanakan pekerjaan dengan didasari kematangan iman dan taqwa serta dibekali dengan penguasaan ilmu pengetahuan dan teknologi memberikan hasil yang akan membawa nama baik/harum bagi yang bersangkutan maupun keluarganya. Motif kapal sangat mempunyai arti selalu waspada dalam mengarungi kehidupan. Motif kuao berhias mempunyai arti dengan cara instropeksi diri sendiri untuk mengetahu kelemahan dan potensi diri. Motif merak ngeram mengartikan bahwa jasa pengorbanan dan kasih sayang ibu dan menghormati orang tua. Motif tampok manggis mengartikan pentingnya kepribadian, perilaku dan penampilan yang baik. Untuk melihat perkembangan aset pemilik IKM dapat dilihat dalam Tabel 2.

Dari Tabel 2 menunjukkan bahwa adanya perkembangan modal awal dan penjualan produk dari industri batik Jambi meningkat. Nilai penjualan sudah mencapai Rp.720.000.000,- Hal ini menunjukkan adanya kekuatan Daya Saing IKM untuk memperkuat posisi batik Jambi di pasar lokal, nasional dan internasional. Dari identifikasi responden IKM batik Jambi, berdasarkan aspek gender dapat dilihat dalam Tabel 3. 
Berdasarkan Tabel 3 menginformasikan bahwa dari 149 responden, ada $84 \%$ wanita yang mendominasi usaha batik Jambi, Semua kegiatan proses produksi dan pemasaran dilakukan di rumah. Untuk mengetahui rata-rata usia responden batik Jambi dapat dilihat dalam Tabel 4.

Tabel 4 menggambarkan dari total 149 responden $34 \%$ yang menggeluti usaha batik Jambi berusia 41 sampai 50, dan hanya $20 \%$ kurang dari $31-40$ tahun, ini menunjukkan bahwa perlu adanya regenerasi untuk pengembangan, pembinaan bagi perajin batik di usia yang penuh dengan inovasi dan semangat tinggi untuk bersaing, supaya memperkuat posisi daya saing batik Jambi di masa yang akan datang.

Rata-rata perajin batik Jambi berpendidikan SMA sebesar $43 \%$, ini menunjukkan bahwa IKM batik Jambi memiliki SDM yang memadai untuk beradaptasi dengan perkembangan IPTEK dalam upaya peningkatan Daya Saing.
Tabel 4. Rekapitulasi Jumlah Responden Berdasarkan Usia

\begin{tabular}{|c|c|c|}
\hline Usia (tahun) & Jumlah & $\%$ \\
\hline$\leq 30$ & 24 & $16 \%$ \\
\hline $31-40$ & 30 & $20 \%$ \\
\hline $41-50$ & 51 & $34 \%$ \\
\hline$\geq 51-$ & 44 & $30 \%$ \\
\hline Total & 149 & $100 \%$ \\
\hline
\end{tabular}

Sumber: Data Primer (diolah 2011)

Tabel 5. Rekapitulasi Pendidikan Responden

\begin{tabular}{lcc}
\hline \multicolumn{1}{c}{ Pendidikan } & Jumlah Responden & \% \\
\hline SD & 6 & $4 \%$ \\
SMP & 37 & $25 \%$ \\
SMA & 64 & $43 \%$ \\
Diploma & 12 & $8 \%$ \\
S1 & 30 & $20 \%$ \\
\hline Jumlah & 149 & $100 \%$
\end{tabular}

Sumber: Data primer (diolah 2011)

Tabel 6. Rekapitulasi Hasil Uji Validitas Instrumen Penelitian

\begin{tabular}{|c|c|c|c|c|}
\hline Variabel & Indikator & Korelasi & Sig & Keterangan \\
\hline \multirow{10}{*}{$\mathrm{X} 1$} & X1.1. Spesifikasi produk & 0,701 & 0,000 & Valid \\
\hline & X1.2. Tingkat kapasitas produk & 0,891 & 0,000 & Valid \\
\hline & X1.3. Harga produk & 0,796 & 0,000 & Valid \\
\hline & X1.4. Tingkat inovasi produk & 0,725 & 0,000 & Valid \\
\hline & X1.5. Biaya produksi & 0,605 & 0,000 & Valid \\
\hline & X1.6. Posisioning batik Jambi & 0,891 & 0,000 & Valid \\
\hline & X1.7 Efisiensi proses produksi batik Jambi & 0,891 & 0,000 & Valid \\
\hline & X1.8 Proses perwarnaan batik Jambi & 0,294 & 0.041 & Valid \\
\hline & X1.9 Strategi pemasaran batik Jambi & 0,619 & 0,000 & Valid \\
\hline & X1.10 Desain batik Jambi & 0,398 & 0,005 & Valid \\
\hline \multirow{8}{*}{$\mathrm{X} 2$} & X2.1. Kapasitas infrastuktur & 0,936 & 0,000 & Valid \\
\hline & X2.2. Sumber daya alam & 0,876 & 0,000 & Valid \\
\hline & X2.3. Kesesuain modal fisik & 0,542 & 0,000 & Valid \\
\hline & X2.4. Sarana dan prasarana alat-alat produksi & 0,596 & 0,000 & Valid \\
\hline & X2.5 Prasarana jalan dan transportasi & 0,684 & 0,000 & Valid \\
\hline & X2.6 Sarana dan prasarana penyediaan air & 0,525 & 0,000 & Valid \\
\hline & X2.7 Sarana dan prasarana pasar & 0,638 & 0,000 & Valid \\
\hline & $\mathrm{X} 2.8$ infrastruktur lembaga pendidikan & 0,528 & 0,000 & Valid \\
\hline \multirow{14}{*}{$\mathrm{X} 3$} & X3.1. Konsisten peraturan dan kebijakan & 0,909 & 0,000 & Valid \\
\hline & X3.2. Partisipasi down up & 0,444 & 0,001 & Valid \\
\hline & X3.3. Peraturan dan kebijakan & 0,891 & 0,000 & Valid \\
\hline & X3.4. Mudah dan konsistensi ijin usaha baru & 0,444 & 0,003 & Valid \\
\hline & X3.5 Peraturan pusat dan PEMDA & 0,891 & 0,000 & Valid \\
\hline & X3.6 Peraturan PEMDA (mendistorsi harga) & 0,440 & 0,003 & Valid \\
\hline & X3.7 Kebijakan pemerintah pada IKM batik & 0,958 & 0,000 & Valid \\
\hline & X3.8 Kemudahan perijinan ekspansi ke LN & 0,958 & 0,000 & Valid \\
\hline & X3.9 Kebijakan Pemerintah (proteksi) & 0,835 & 0,000 & Valid \\
\hline & X3.10 Bantuan manajemen & 0,901 & 0,000 & Valid \\
\hline & X3.11 Memberikan bantuan teknik terhadap & 0,920 & 0,000 & Valid \\
\hline & X3.12 memberikan bantuan modal & 0,547 & 0,000 & Valid \\
\hline & X3.13 Pembimbingan dan pengarahan & 0,290 & 0,043 & Tidak valid \\
\hline & X3.14 Peraturan pemda (perdagangan) & 0,935 & 0,000 & Valid \\
\hline
\end{tabular}


Lanjutan Tabel 6

\begin{tabular}{clccc}
\hline Variabel & Indikator & Korelasi & Sig & Keterangan \\
\hline & X3.15 Kebijakan PEMDA dalam pemasaran & 0,326 & 0,022 & Tidak Valid \\
& X4.1. Ketersediaan tenaga kerja & 0,450 & 0,001 & Valid \\
X4.2. Kualitas kerja sumberdaya manusia & 0,413 & 0,003 & Valid \\
& X4.3. Kualitas angkatan kerja & 0,513 & 0,000 & Valid \\
& X4.4. Pendidikan & 0,597 & 0,000 & Valid \\
& X4.5 pelatihan & 0,831 & 0,000 & Valid \\
& X4.6 Sikap dan nilai budaya tenga kerja & 0,492 & 0,000 & Valid \\
& X4.7 Kualitas hidup tenaga kerja & 0,868 & 0,000 & Valid \\
\hline \multirow{4}{*}{ X5.1. Teknologi pembuatan batik } & 0,768 & 0,000 & Valid \\
& X5.2. Intensitas kegiatan penelitian & 0,335 & 0,018 & Tidak Valid \\
& X5.3. Kerjasama litbang dan universitas & 0,408 & 0,004 & Valid \\
& X5.4. Penyesuaian teknologi informasi & 0,377 & 0,008 & Tidak Valid \\
& X5.5 Teknologi proses produksi batik & 0,720 & 0,000 & Valid \\
& X5.6 tenaga ahli IPTEK & 0,525 & 0,000 & Valid \\
& X.7 kualifikasi SDM & 0,809 & 0,000 & Valid \\
\hline & Y.6.1 Perkembangan omset & 0,555 & 0,000 & Valid \\
& Y.6.2 Tingkat perkembangan usaha & 0,469 & 0,001 & Valid \\
& Y6.3 Pangsa pasar batik Jambi di pasar lokal & 0,591 & 0,000 & Valid \\
& Y.6.4 Pangsa pasar & 0,591 & 0,000 & Valid \\
& Y.6.5 Volume penjualan batik Jambi & 0,591 & 0,000 & Valid \\
\hline
\end{tabular}

Sumber: Data primer (diolah 2011)

\section{Uji Validitas dan Reliabilitas}

Uji validitas dilakukan untuk menguji kesahihan atau keandalan butir-butir pertanyaan yang terdapat pada angket penelitian. Uji validitas dan reliabilitas kuisioner dilakukan dengan teknik korelasi Product Moment Pearson dan Alpha Cronbach terhadap 149 responden, dengan syarat validasi signifikansi $<5 \%$, hasil uji instrumen seperti dalam Tabel 6.

Menurut Sekaran (2007) uji konsistensi Alpha Cronbach, reliabilitas tinggi jika koeffisien $\alpha \geq 0,5$ atau koefisien reliability Alpha lebih dari 0,7 menunjukkan kuisioner reliable dan hasil uji dalam Tabel 7.

Tabel 7. Rekapitulasi Hasil Uji Reliabilitas Instrumen Penelitian

\begin{tabular}{lcc}
\hline \multicolumn{1}{c}{ Faktor } & $\begin{array}{c}\text { Nilai } \\
\text { Alpha }\end{array}$ & Keterangan \\
\hline X1. Produk & 0,7999 & Reliabel \\
X2. Infrastruktur & 0,7275 & Reliabel \\
X3. Kebijakan pemerintah & 0,7653 & Reliabel \\
X4. Sumber Daya Manusia & 0,7751 & Reliabel \\
X5. IPTEK & 0,7220 & Reliabel \\
Y. Daya saing batik Jambi & 0,8201 & Reliabel \\
\hline
\end{tabular}

Sumber: Data Primer (diolah 2011)

Dari Tabel 6 dan 7 menunjukkan bahwa semua hasil analisis instrumen penelitian sudah menjawab hipotesis validitas dan reliabilitas kuisioner, karena secara statistik telah memenuhi persyaratan yaitu $r$ hasil positif dan lebih besar dari $r$ tabel $(0,325)$ dan signifikansi $<5 \%$ sehingga instrumen dalam variabel penelitian tersebut menjadi 38 instrumen yang dilanjutkan untuk menjawab hipotesis yang dibuat dengan menggunakan pendekatan analisis faktor dan regresi berganda.

Analisis faktor bertujuan untuk menyederhanakan data dan menentukan beberapa set variabel baru (faktor). Dengan cara mengidentifikasi 49 variabel observable yang diyakini sebagai sumber yang melandasi seperangkat variabel unobservable.

Melalui tahapan analisis faktor, yaitu penyusunan Matriks Korelasi, Ekstraksi Faktor, Rotasi Faktor, dan Interprestasi Faktor (Sekaran, 2007; Syaifuddin, 2004).

Berdasarkan dari hasil analisis faktor tahap satu diketahui bahwa 97\% dari 25 variabel observable korelasi KMO di atas 0,5 dan signifikansi $<0,01$, dan hanya empat variabel observable yang tidak memenuhi persyaratan anti image correlation (MSA). Variabel unobservable yang memiliki nilai $\mathrm{KMO}>0,5$ seperti dalam Tabel 8 .

Metode ekstraksi faktor yang digunakan adalah Principle Component Analysis (PCA), penentuan jumlah faktor berdasarkan pada nilai eigen value $>$ 1,0 (Sekaran, 2007). Jumlah faktor inti yang didasarkan pada kriteria tersebut, dapat dilihat dalam Tabel 9. 
Tabel 8. Rekapitulasi Variabel Yang Memenuhi Syarat MSA

\begin{tabular}{clcc}
\hline Code & \multicolumn{1}{c}{ Nama Variabel } & KMO & Barlett's Test of Sphericity \\
\hline X1 & Produk & 0,500 & 23,044 \\
X2 & Infrastruktur & 0,668 & 85,883 \\
X3 & Kebijakan pemerintah & 0,560 & 73,044 \\
X4 & Sumber Daya Manusia & 0,693 & 178,779 \\
X5 & IPTEK & 0,567 & 213,636 \\
Y & Daya saing batik Jambi & 0,567 & 213,636 \\
\hline
\end{tabular}

Sumber: Data Primer (diolah 2011)

Tabel 9. Rekapitulasi Faktor Inti

\begin{tabular}{ccccc}
\hline No & Faktor & Eigenvalue & $\begin{array}{c}\text { Percentage of } \\
\text { Variance }\end{array}$ & Cumulative Percentage of Variance \\
\hline 1 & X1 & 1,031 & 51,539 & 51,539 \\
2 & X2 & 2,361 & 33,731 & 33,731 \\
3 & X3 & 3,541 & 88,522 & 88,522 \\
4 & X4 & 3,264 & 81,601 & 81,601 \\
5 & X5 & 3,120 & 44,575 & 44,575 \\
& Y & 3,120 & 44,575 & 44,575 \\
\hline
\end{tabular}

Sumber: Data Primer (diolah 2011)

Tabel 10. Hasil Uji Multikolinieritas

\begin{tabular}{lccc}
\hline \multicolumn{1}{c}{ Variabel } & Tolerance & $\begin{array}{c}\text { Variance Inflation } \\
\text { Factor / VIF }\end{array}$ & Keterangan \\
\hline Produk (X1) & 0,007 & 1,500 & Non Multikolinieritas \\
Infrastruktur (X2) & 0,003 & 2,872 & Non Multikolinieritas \\
Kebijakan Pemerintah (X3) & 0,916 & 1,090 & Non Multikolinieritas \\
SDM (X4) & 0,800 & 1,250 & Non Multikolinieritas \\
IPTEK (X5) & 0,003 & 3,980 & Non Multikolinieritas \\
\hline
\end{tabular}

Sumber: Data Primer (diolah 2011)

Dari Tabel 8 dan 9 diketahui bahwa teknik analisis yang digunakan dalam analisis faktor ini sudah tepat dengan nilai variabel component matrix $>0,5$.

\section{Uji Asumsi Klasik}

Hasil pengujian asumsi klasik terhadap normalitas data, uji multikolinearitas, uji heteroskedastisitas, uji autokorelasi dan linearitas untuk melihat apakah dalam sebuah model regresi, variabel bebas dan variabel terikat $(\mathrm{Y})$ berdistribusi normal tanpa ada multikolineritas dan autokorelsi dalam model regresi. Hasil tersebut untuk dilanjutkan analisis regresi berganda, seperti dalam Tabel 10

Dengan nilai VIF dan Tolerance > 10, berarti kelima variabel bebas dalam model regresi tersebut tidak ada gejala saling berhubungan (Non Multikolinieritas) dan hasil uji D-W pada bagian Model Summary membuktikan bahwa angka D-W sebesar 2,217 pada taraf $\alpha=0,05$, tidak terdapat gejala autokorelasi dalam model regresi.

\section{Uji Regresi Berganda (Multiple Regression Analysis)}

Analisis regresi berganda dilakukan untuk mengetahui pengaruh variabel bebas terhadap variabel terikat secara simultan danparsial serta menjawab hipotesis penelitian. Hasil analisis regresi berganda seperti dalam Tabel 11.

Dari Tabel 11 menunjukkan angka $\mathrm{R}$ sebesar $0,885>0,5$ ada korelasi atau hubungan antara variabel dependen, dengan lima variabel bebas secara simultan kuat. Angka R Square atau koefisien determinasi $\left(\mathrm{R}^{2}\right)$ adalah 0,783 menunjukkan peningkatan Daya Saing batik Jambi bisa dijelaskan oleh variasi dari ke lima faktor yang ada dalam model regresi. Nilai R menunjukkan bahwa variabel observable memiliki kontribusi efektif dan cukup besar dan 25,5\% (100\%-75,7\%) dijelaskan oleh variabel observable lain diluar model. Nilai Standar Error of Estimate (SEE) adalah 0,882 dengan variasi kesalahan (effect outlier) sekitar 14,5\% dari setiap variabel observable, akan membuat model regresi 
semakin tepat dalam memprediksi Daya Saing batik Jambi.

Dari uji Anova atau $\mathrm{F}$ test di peroleh $\mathrm{F}$ hitung sebesar 30,096, dengan tingkat signifikansi 0,000 jauh lebih kecil dari 0,05 maka model regresi bisa dipakai untuk memprediksi peningkatan Daya Saing batik Jambi secara simultan lima variabel bebas tersebut mempunyai pengaruh yang positif terhadap peningkatan Daya Saing batik Jambi.

Dari analisis regresi korelasi dan berdasarkan Tabel 11, maka diperoleh persamaan regresi bergand adalah:

$Y=a+\beta 1 X 1+\beta 2 X 2+\beta 3 X 3+\beta 4 X 4+\beta 5 X 5$

Daya Saing $=0,460+\mathrm{X} 10,022+\mathrm{X} 2$ 1,795+ $\mathrm{X} 30,001+\mathrm{X} 40,147+\mathrm{X} 50,503$.

Dengan nilai $\mathrm{F}$ hitung $=30,968>\mathrm{F}$ Tabel $=$ 2,941, Probabilitas $=0,000$, dan taraf signifikansi $\alpha$ $=5 \%$ model regresi berganda dapat dipakai untuk meningkatkan Daya Saing batik Jambi. Secara simultan variabel bebas berpengaruh positif terhadap variabel terikat, dengan nilai $\mathrm{R}$ 0,885>0,05.Hasil analisis regresi antar variabel bebas terhadap variabel terikat secara parsial signifikan ditunjukkan dari nilai t hitung $>\mathrm{t}$ tabel atau signifikan $\mathrm{t}<5 \%$, dan variabel independen yang berpengaruh tidak signifikan ditunjukkan dari nilai $\mathrm{t}$ hitung $<\mathrm{t}$ tabel atau sig $\mathrm{t}>\alpha$ 0,05(uji t) hasil uji dalam Tabel 12.

Dari hasil rekapitulasi hasil analisis regresi berganda pada Tabel 12 membuktikan secara parsial tingkat signifikansi ada dua variabel bebas yang tidak signifikan yaitu Produk (X1) sebesar 0.221 > 0.05 dan Kebijakan Pemerintah (X3) dan yang signifikan seperti dalam Tabel 13.

Dari data Tabel 13 menunjukkan bahwa variabel Infrastruktur, SDM, dan IPTEK mempunyai pengaruh positif signifikan terhadap Daya Saing batik Jambi, karena nilai signifikansi t $>5 \%$ dan Infrastruktur, mempunyai nilai Beta sebesar 0,647 dan sig $t$ hanya $0,000 \%<5 \%$, berarti variabel Infrastruktur mempunyai pengaruh dominan. Indikator infrastruktur meliputi sarana produksi, fasilitas air bersih, jalan atau kemudahan akses informasi,

Tabel 11. Hubungan Variabel Independen Terhadap Variabel Dependen Secara Simultan

\begin{tabular}{|c|c|c|c|c|}
\hline Variabel & $\mathrm{B}$ & thitung & Sig t & Beta \\
\hline Constant & 0,460 & 2,941 & 0,005 & \\
\hline Produk (X1) & 0,022 & 1,127 & 0,211 & 0,110 \\
\hline Infrastruktur (X2) & 1,795 & 5,372 & 0,000 & 6,474 \\
\hline Kebijakan Pemerintah (X3) & 0,001 & $-1,974$ & 0,009 & $-0,008$ \\
\hline $\mathrm{SDM}(\mathrm{X} 4)$ & 0,147 & 12,390 & 0,000 & 0,123 \\
\hline IPTEK (X5) & 0,503 & 0,397 & 0,000 & $-5,385$ \\
\hline$=0,885$ & & & & \\
\hline$=0,785$ & & & & \\
\hline Adjusted R Square $=0,757$ & & & & \\
\hline$=30,968$ & & & & \\
\hline$=2,216$ & & & & \\
\hline$=0,000$ & & & & \\
\hline$=0,882$ & & & & \\
\hline
\end{tabular}

Sumber: Data Primer(diolah 2011)

Tabel 12 Rekapitulasi Hasil Uji Parsial

\begin{tabular}{|c|c|c|c|c|c|c|c|c|}
\hline \multirow[t]{2}{*}{ Model } & \multicolumn{2}{|c|}{$\begin{array}{c}\text { Unstandardized } \\
\text { Coefficients }\end{array}$} & \multirow{2}{*}{$\begin{array}{c}\text { Standardized } \\
\text { Coefficients } \\
\text { Beta } \\
\end{array}$} & \multirow[t]{2}{*}{$\mathbf{t}$} & \multirow[t]{2}{*}{ Sig. } & \multicolumn{3}{|c|}{ Correlations } \\
\hline & $\mathbf{B}$ & Std. Error & & & & Zero-order & Partial & Part \\
\hline Constant & 0,460 & 0,156 & & 2,941 & 0,005 & & & \\
\hline $\mathrm{X} 1$ & $-0,285$ & 0,225 & $-1,106$ & $-1,270$ & 0,211 & $-0,015$ & $-0,190$ & $-0,009$ \\
\hline $\mathrm{X} 2$ & 1,795 & 0,334 & 6,474 & 5,372 & 0,000 & $-0,011$ & 0,634 & 0,382 \\
\hline $\mathrm{X} 3$ & $-0,001$ & 0,013 & $-0,008$ & $-0,104$ & 0,917 & $-0,053$ & $-0,016$ & $-0,007$ \\
\hline $\mathrm{X} 4$ & 0,147 & 0,012 & 0,986 & 12,399 & 0,000 & 0,795 & 0,884 & 0,881 \\
\hline $\mathrm{X} 5$ & $-1,503$ & 0,397 & $-5,382$ & $-3,790$ & 0,000 & $-0,010$ & $-0,500$ & $-0,269$ \\
\hline
\end{tabular}

Sumber: Data Primer (diolah 2011)

Tabel 13. Rekapitulasi Signinfikansi Parsial

\begin{tabular}{lccccccc}
\hline \multicolumn{1}{c}{ Variabel } & B & Std. Error & Beta & t hitung & Sig.t & A & Keterangan \\
\hline Infrastruktur (X2) & 1,795 & 0,334 & 6,474 & 5,372 & 0,000 & 0,05 & Signifikan \\
SDM (X4) & 0,147 & 0,012 & 0,986 & 12,399 & 0,000 & 0,05 & Signifikan \\
IPTEK (X5) & $-1,503$ & 0,397 & 5,382 & $-3,790$ & 0,000 & 0,05 & Signifikan \\
\hline Sumb
\end{tabular}

Sumber: Data Primer (diola 2011) 
transportasi dan sarana pemasaran yang mendukung peningkatan Daya Saing batik Jambi.

Pengujian hipotesis pertama ini menduga bahwa secara simultan bahwa faktor produk (X1), faktor infrastruktur (X2), faktor kebijakan pemerintah (X3), faktor SDM (X4) dan faktor IPTEK (X5) mempunyai kontribusi yang signifikan terhadap Daya Saing IKM batik Jambi dengan nilai koefisien determinasi Adjusted $R^{2}=0,757$ membuktikan hubungan kuat antara variabel bebas dengan variabel terikat sebesar $75,7 \%$. Dengan demikian pernyataan hipotesis pertama yang dirumuskan dalam penelitian secara statistik dapat diterima dan terbukti kebenarannya.

Hipotesis kedua, berdasarkan uji t pada Tabel 12 dan 13, variabel Produk dan Kebijakan Pemerintah secara parsial ditingkatkan atau diturunkan maka tidak memberikan kontribusi untuk meningkatkan Daya Saing batik Jambi karena nilai signifikansi $t>$ $5 \%$.

Dengan demikian hipotesis kedua secara statistik tidak dapat di terima dan terbukti kebenarannya. Untuk mengetahui variabel bebas yang mempunyai pengaruh yang dominan terhadap Daya Saing dari nilai $\beta$ sebesar 0,647 dan sig t hanya $0,000<5 \%$, berarti variabel Infrastruktur mempunyai pengaruh dominan dibandingkan dengan variabel bebas lainnya terhadap Daya Saing batik Jambi. Hasil hipotesi ke dua dalam penelitian ini berbeda dengan hasil penelitian Arfan et al. (2008) mengatakan bahwa faktor-faktor yang mempengaruhi pengembangan kreativitas industri kerajinan batik adalah SDM yang tinggi dan Peran Pemerintah.

\section{Interpretasi Hasil Penelitian}

Untuk melihat kontribusi variabel bebas menggunakan nilai standarized beta. Nilai Beta variabel X1 sebesar - 0,110, menunjukkan bahwa apabila variabel produk belum memberikan kontribusi kuat terhadap Daya Saing batik Jambi, perlu ada standarisasi produk, memperbanyak variasi batik. Nilai Beta variabel X2 $=0,647$, menunjukkan bahwa infrastruktur cukup besar memberikan kontribusai sebesar 0,647 untuk meningkatkan Daya Saing batik Jambi. Nilai Beta variabel X3 sebesar 0,008, menunjukkan bahwa Kebijakan Pemerintah belum maksimal berkontribusi terhadap peningkatan Daya Saing batik Jambi, karena belum efektif dan efisien regulasi dan peraturan pemerintah untuk meningkatkan Daya Saing IKM batik Jambi.

Nilai Beta variabel X4 sebesar 0,986, menunjukkan bahwa SDM memberikan peranan penting sebesar 0,986 untuk meningkatkan untuk mening- katkan Daya Saing batik Jambi karena dalam hal ini kehandalan dan kecermatan dalam membatik diperlukan.

Nilai Beta variabel X5 sebesar 0,538, menunjukkan bahwa IPTEK memberikan kontribusi 0,538 tidak signifikan untuk meningkatkan untuk meningkatkan Daya Saing batik Jambi, ini disebabkan penerapan dan adopsi teknologi masih rendah dan dalam bidang penelitian serta pengembangan produk dan pasar rendah.

Pembuktian kebenaran hipotesis pertama dilakukan dengan membandingkan nilai signifikansi $\mathrm{F}$ hitung dengan $\alpha=5 \%$, dan berdasarkan hasil uji regresi berganda dari pengolahan data dengan SPSS (Statistical Product and Service Solution) diperoleh nilai signifikansi dan probabilitas sebesar $0,000<\alpha$ $5 \%$, atau dilihat dari perbandingan $\mathrm{F}$ hitung dengan $\mathrm{F}$ Tabel dan F hitung $=30,968>\mathrm{F}$ Tabel $=2,941$ dan berdasarkan hasil dari analisis regresi berganda pada Tabel 11,12 dan 13 menunjukkan hanya ada tiga variabel bebas yang mempunyai pengaruh kuat terhadap meningkatkan Daya Saing batik Jambi.

Penambahan dan perbaikan Infrastruktur prasarana yang berkaitan dengan kelancaran produksi dan pemasaran batik Jambi menjadi tombak kekuatan dalam Daya Saing batik Jambi. Penambahan fasilitas produksi, memperbanyak kegiatan pemasaran seperti diadakan pameran, kerjasama dengan instansi pemerintahan, kebutuhan air bersih, memperbaiki sistem telekomunikasi, memperbaiki kelancaran transportasi merupakan hal yang memberikan kontribusi positif untuk meningkatkan daya saing batik Jambi dalam hal ini untuk mendukung proses produksi dan hasil produksi dengan kualitas yang terbaik. Pembangunan jembatan mempermudah dan mempercepat alur distribusi produk serta membuka akses pembeli untuk datang langsung ke sentra produksi. Penambahan sarana dan prasarana lembaga pelatihan menunjang Daya saing batik Jambi.

Meningkatkan sarana dan fasilitas pemasaran batik Jambi sudah dibangun showroom Dewan Kerajinan Nasional Daerah Jambi, Art Shop Kembang Seri Wisma Perwakilan Jambi-Jakarta, Showroom Kembang Seri Jambi, Balai Kerajinan Rakyat Selaras Pinang Masak Mudung Laut Seberang Jambi dan Galeri Batik Berkah Jambi. Dengan showroom ini produk batik dapat dengan mudah memasarkannya ke masyarakat.Selain itu batik Jambi juga di pasarkan dibeberapa pasar modern dan boutique-boutique khusus yang tersebar di pusat perbelanjaan modern di Jambi. Dengan kelancaran distribusikan pemasaran ke daerah-daerah lain di Indonesia dan di mancanegara sekalipun dapat meningkatkan pangsa pasar. 
Sumber Daya Manusia yang memiliki kompetensi sangat dibutuhkan dalam produksi batik Jambi, hampir 90\% kegiatan dilakukan dengan menggunakan skill dan tenaga kerja manusia. Oleh karena itu, sangat dibutuhkan kompetensi dan keahlian perajin dalam proses produksi. Selain itu kerjasama dan loyalitas perajin harus ada karena proses membatik membutuhkan waktu, kesabaran dan ketelitian. Supaya daya saing meningkat SDM khususnya pembatik harus diregenerasi untk meningkatkan ketersedian SDM dan angkatan kerja di masa yang akan datang, karena saat ini hanya $16 \%$ perajin batik berusia kurang dari 30 tahun.

Peningkatan pelatihan angkatan kerja yang tersistem dan terencana untuk meningkatkan SDM perajin dan pemilik batik di Jambi harus di program untuk meningkatkan kualitas SMD perajin batik Jambi dan supaya ketersediaan SDM terjamin. Dalam IKM harus diciptakan SDM yang kreatif, inovatif dan memiliki keterampilan melalui pendidikan dan pelatihan perajin untuk mendukung proses produksi dengan standarisasi pasar, jika SDM ingin memiliki peluang bersaing (Timpe, 1992).

Beradaptasi dan melakukan perubahan dan perkembangan dalam aspek IPTEK sangat penting untuk kinerja suatu usaha yang bersaing (Rahayu \& Putri, 2010). Disadari bahwa perkembangan IPTEK dunia berkembang sangat cepat dan perkembangan ini harus diketahui arahnya. Dengan perpaduan tersebut IPTEK dan kemampuan manusia yang matang dan dengan sedikit "sense of art", industri kreatif di dunia ini mulai tercipta sedikit demi sedikit. Inovasi motif batik-batik bisa digambar dalam pemodelan menggunakan program komputerisasi. Penelitian dengan universitas dan instansi pemerintah untuk mengembankan motif dan desain batik-batik lama mau pun baru dapat dikembangkan secara langsung hingga memenuhi standard dan selera konsumen. Menurut Simatupang (2008) bahwa teknologi proses produksi dalam mengembangkan batik diperlukan untuk meningkatkan kreativitas dan manfaat desain batik yang mengikuti selera pasar. Dengan proses produksi yang tinggi dan memenuhi standar pasarakan memberi nilai tambah untuk meningkatkan Daya Saing batik Jambi.

\section{SIMPULAN DAN SARAN}

Dari hasil analisa regresi berganda dan pengujian hipotesis penelitian, maka dapat disimpulkan secara simultan variabel Produk, Infrastruktur, Kebijakan Pemerintah, SDM dan IPTEK berpengaruh terhadap Daya Saing batik Jambi. Untuk meningkatkan pangsa pasar batik Jambi, maka kelima variabel bebas tersebut harus diimplemntasi secara sinergis untuk mendapatkan kekuatan dalam persaingan batik di pasar nasional maupun global apalagi dengan terbukanya pasar perdagangan dunia, sehingga produk-produk garmen bisa masuk pasar Indonesia.

Peningkatan Infrastruktur, IPTEK dan SDM mempunyai peran yang strategis dalam proses produksi batik Jambi, pemasaran dan perluasan pangsa pasar untuk meningkatkan Daya Saing batik Jambi.

Perlu adanya kerjasama antara Pemerintah daerah Jambi dengan universitas untuk memberikan pelatihan dan pendidikan kepada IKM dan perajin batik dalam meningkatkan kompetensi mereka untuk pengembangan dan pemberdayaan SDM dengan pelatihan membatik yang rutin dalam hal pengembangan perajin batik, modifikasi motif, model dan inovasi batik. Penetapan standar produksi batik Jambi dengan memperhatikan proses produksi. Mempermudah pendistribusian dan pemasaran batik Jambi. IKM batik harus melakukan regenerasi perajin batik dengan merekrut masyarakat usia antara 2545 tahun. Saran untuk penelitian selanjutnya adalah untuk meneliti faktor yang berhubungan dengan strategi pemasaran batik Jambi.

\section{DAFTAR REFERENSI}

Arfan, B., Sriyanto \& Amalia. 2009. Analisa FaktorFaktor Yang Mempengaruhi Pengembangan Kreativitas Industri Kerajinan Batik. J@TI Undi, IV(1).

Badan Pusat Statistik. 2010. Keadaan Ketenagakerjaan Indonesia Februari 2010. No. 33/05/ Th. XIII. 10 Mei 2010. Jakarta, Indonesia.

Daryono \& Wahyudi. 2008. Analisis Kompetensi Produk Unggulan Daerah Pada Batik Tulis dan Cap Solo di Dati II Kota Surakarta. Jurnal Ekonomi Pembangunan, 9(2): 184-197.

Devina, R. 2010. Analisis Strategi Positioning "Ethnic Batik" Dalam Komunikasi Pemasaran (Studi Kasus: CV. Erfas Jaya-Ethnic Batik). Tesis Tidak Dipublikasikan. Surabaya: Universitas Airlangga.

Dinas Perindustrian dan Perdagangan Provinsi Jambi. 2011. Profil Industri Batik (http://www.kotajambi.go.id/id/index.php?option=com_content \&task $=$ view $\& i d=161 \&$ Itemid $=153 \&$ limit $=1 \&$ limitstart=2, diakses 12 Juli 2011.

Piter, A. 2002. Daya Saing Daerah Konsep dan Pengukurannya di Indonesia. Yogyakarta: BPFE.

Porter, M.E. 2000. Keunggulan Bersaing. Terjemahan. Jakarta: Binapura Aksara. 
Rahayu, N. \& Putri S. 2010. Rancangan Perbaikan Kualitas Produk Batik Solo Dengan Menerapkan Model Quality Function Deployment (QFD). Skripsi Tidak Dipublikasikan. Surabaya: Universitas Airlangga.

Rostow, W. 1999. Stages of Economic Growth. Third Edition. New York: Hambridge University Press.

Sekaran, U. 2007. Metodologi Penelitian Untuk Bisnis. Jakarta: Salemba Empat.

Simatupang, T.M. 2008. Perkembangan Industri Kreatif. Pikiran Rakyat, pp. 28.

Syaifuddin, A. 2004. Metode Penelitian. Cetakan Keempat. Yogyakarta: Pustaka Pelajar.
Tambunan, I. 2011. Ketika Batik Jambi Mengalami "Booming". (http://nasional.kompas.com/read/ 2011/04/01/04373767/, diakses 12 Juli 2011).

Theodurus, K. 2007. Analisis Faktor-Faktor yang Mempengaruhi Daya Saing Industri Kecil (Studi di Sentra Industri Kecil Cor Logam Pasuruan Jawa Timur). Tesis Tidak Dipublikasikan. Malang: Universitas Brawijaya.

Timpe, A. D. 1992. Kreativitas: Seri Manajemen Sumber Daya Manusia. Terjemahan oleh Sopyan Cikmat. Jakarta: Elex Media Komputindo. 